$$
\text { 年 }
$$

Sammlung Metzler

Band 242 
Kurt Bartsch

\section{Ingeborg Bachmann}

J. B. Metzlersche Verlagsbuchhandlung Stuttgart 


\section{Für Bruni}

CIP-Kurztitelaufnahme der Deutschen Bibliothek

Bartsch, Kurt:

Ingeborg Bachmann / Kurt Bartsch.

- Stuttgart : Metzler, 1988

(Sammlung Metzler ; Bd. 242)

ISBN 978-3-476-10242-3

NE: GT

ISBN 978-3-476-10242-3

ISBN 978-3-476-03944-6 (eBook)

DOI 10.1007/978-3-476-03944-6

ISSN 05583667

SM 242

Dieses Werk einschließlich aller seiner Teile ist urheberrechtlich geschützt. Jede Verwertung außerhalb der engen Grenzen des Urheberrechtsgesetzes ist ohne Zustimmung des Verlages unzulässig und strafbar. Das gilt insbesondere für Vervielfältigungen, Übersetzungen, Mikroverfilmungen und die Einspeicherung und Verarbeitung in elektronischen Systemen.

(C) 1988 Springer-Verlag GmbH Deutschland

Ursprünglich erschienen bei J. B. Metzlersche Verlagsbuchhandlung und Carl Ernst Poeschel Verlag GmbH in Stuttgart 1988 


\section{Inhaltsverzeichnis}

Vorbemerkung .............. VII

1. Einleitung: Ingeborg Bachmanns Werk im Widerstreit gesellschaftlicher Erwartungen . . . 1

1.1 Bachmanns Eintritt in die literarische Öffentlichkeit: Die auratische Lyrikerin . . . . . . . . . . . 1

1.2 Die Ablehnung der »gefallenen Lyrikerin «: Vom Dreißigsten Jabr zu Malina . . . . . . . . . . 8

1.3 Das neuerwachte Interesse an Ingeborg Bachmann:

Die Simultan-Erzählungen - Werkausgabe Frauenbewegung ............

2. Theoretisches . . . . . . . . . . . 17

2.1 Abgrenzung von Philosophie und Literatur:

Die Dissertation und die Wittgenstein-Essays . . . . 18

2.2 Literatur als Utopie: Die Musil-Essays und die Frankfurter Vorlesungen (I) . . . . . . . . . . . . . 24

2.3 »Ein Utopia der Sprache«:

Die Frankfurter Vorlesungen (II) _ . . . . . . . . 31

2.4 Die Fragwürdigkeit des Ichs:

Die Frankfurter Vorlesungen (III) . . . . . . . . . 34

3. Das literarische Werk . . . . . . . . . . . 37

3.1 Frühe Texte . . . . . . . . . . . . . . . . . . 37

3.2 Das literarische Werk der fünfziger Jahre . . . . . 51

3.2.1 Die Lyrik (1952-1961) . . . . . . . . . . . . 51

3.2.1.1 Die gestundete Zeit . . . . . . . . . . . . . 53

3.2.1.2 Anrufung des Großen Bären
und Gedichte $1957-1961 \ldots \ldots . . . . . .6 .62$

3.2 .2 Die Hörspiele . . . . . . . . . . . . . . . 76 
3.2.3 Libretti . . . . . . . . . . . . . . . 92

3.2.4 Ungaretti-Übersetzungen . . . . . . . . . . . . . . . . . 97

3.2 .5 Erzählprosa . . . . . . . . . . . . . 98

3.3 Das literarische Werk der sechziger Jahre

(1961-1973) . . . . . . . . . . . . 128

3.3 .1 Lyrik . . . . . . . . . . . . . . . . 128

3.3.2 DerTodesarten-Komplex . . . . . . . . . 134

3.3.2.1 Zum Begriff Todesarten . . . . . . . . . . 134

3.3.2.2 Ein Ort für Zufälle . . . . . . . . . . . . . . . 138

3.3.2.3 Malina und die Fragmente des Todesarten-Zyklus . 142

3.3.2.4 Simultan . . . . . . . . . . . . 158

4. Anhang ............... 175

4.1 Biographischer Abriß . . . . . . . . . . . . 175

4.1.1 1926-1945: Klagenfurt . . . . . . . . 175

4.1.2 1945-1953: Wien . . . . . . . . . . 176

4.1.3 1953-1957: Italien . . . . . . . . . . . . . 179

4.1.4 1957-1963: München, Zürich, Rom . . . . . . . 180

4.1.5 1963-1966: Berlin . . . . . . . . . . 181

4.1.6 1966-1973: Wien in Rom . . . . . . . . 183

4.2 Werkausgaben ............ . . 184

4.2.1 Einzelausgaben vor 1978 . . . . . . . . . . . 185

4.2.2 Teilsammlungen . . . . . . . . . . . . . . 186

4.2.3 Die Werkausgabe von 1978 . . . . . . . . . . . . 187

4.2.4 Ergänzungen zur Werkausgabe . . . . . . . . . 189

4.3 Der Nachlaß . . . . . . . . . . . . . . 191

4.4 Personalbibliographien ... . . . . . . . 191

4.5 Forschungsberichte . . . . . . . . . . 192

5. Literaturverzeichnis . . . . . . . . 193

5.1 Zur Zitierweise . . . . . . . . . . . . 193

5.2 Textausgaben Ingeborg Bachmann . . . . . . . 193

5.3 Texte anderer Autor(inn)en . . . . . . . . . . . . 194

5.4 Literatur über Bachmann . . . . . . . . . . . . . . . . . . . . . . 205

5.5 Weitere Literatur . . . . . . . . . . . . . . . 204

6. Register . . . . . . . . . . . . . 207

6.1 Titelregister . . . . . . . . . . . . . 207

6.2 Namenregister ........... . 209 


\section{Vorbemerkung}

Das Bild Ingeborg Bachmanns in der literarischen Öffentlichkeit ist zwiespältig: man zählt sie zu den Klassikern der deutschsprachigen Literatur, interessiert sich aber nur allzuoft mehr für die Legenden, die sich um ihr Leben und ihre persönliche Erscheinung ranken, als für ihr Werk. Die ältere Generation, durchwegs fasziniert von der Lyrik der fünfziger Jahre, hat ihr den Wechsel zum Erzählgenre nicht verziehen, und die 68erGeneration fand von ihrem Literaturverständnis her keinen $\mathrm{Zu}$ gang zu den Texten der österreichischen Schriftstellerin. Verstellt durch Vorurteile, geriet deren gesellschaftskritische Brisanz nicht ins Blickfeld. Die Literaturwissenschaft nahm Bachmanns Werk bis in die späteren siebziger Jahre kaum und wenn, reduziert auf werkimmanente oder ausschließlich sprachphilosophisch ausgerichtete Fragestellungen, zur Kenntnis. Im letzten Jahrzehnt nun werden neue Lesearten erprobt, die dem Aspekt der Vermittlung geschichtlicher Erfahrung Bachmanns in ihrem Werk und/oder feministischen Fragestellungen das Hauptaugenmerk schenken. Mit der Verschiebung des Erkenntnisinteresses verknüpft sich naturgemäß die Präferenz für die späte erzählende Prosa der Autorin, die weibliches Dasein unter den Bedingungen patriarchalischer Gesellschaftsstrukturen als zentrales Problem thematisiert. Die vorliegende Monographie weiß sich, im Bemühen allerdings, das gesamte literarische und essayistische Werk Bachmanns im Auge zu behalten, den neuen Ausrichtungen der Literaturwissenschaft eng verbunden.

Der Alexander-von-Humboldt-Stiftung (Bonn) danke ich für großzügige Unterstützung, den Erben von Ingeborg Bachmann, Frau Isolde Moser und Herrn Dr. Heinz Bachmann für die Erlaubnis, auszugsweise aus dem literarischen Nachlaß zu zitieren, den Kollegen Robert Pichl (Wien) und Hans Höller (Salzburg) für manche Anregungen, Hinweise und Kritik und nicht zuletzt meiner Familie für viel Geduld und Verständnis. 